\title{
Exposure of Fibrinogen Receptors in Human Platelets by Surface Proteolysis with Elastase
}

\author{
Elizabeth Kornecki, Yigal H. Ehrlich, Daniel D. De Mars, and Robert H. Lenox \\ Neuroscience Research Unit, Departments of Psychiatry and Biochemistry, University of Vermont, \\ College of Medicine, Burlington, Vermont 05405
}

\begin{abstract}
Human platelets that were preincubated with porcine elastase aggregated spontaneously upon the addition of fibrinogen. Maximal aggregation to fibrinogen was observed with platelets pretreated with an elastase concentration of $111 \mu \mathrm{g} / \mathrm{ml}$, and halfmaximal aggregation occurred after treatment with $11 \mu \mathrm{g} / \mathrm{ml}$ elastase. Binding of radiolabeled fibrinogen to elastase-treated platelets was specific, saturable, and showed a single class of $48,400 \pm 9,697$ fibrinogen-binding sites per platelet with a dissociation constant of $6.30 \pm 1.48 \times 10^{-7} \mathrm{M}$. ATP, apyrase, and the stimulators of platelet adenylate cyclase forskolin, prostaglandin $\mathrm{E}_{1}$, prostacyclin, and $N^{6}, 2^{\prime}-O$-dibutyryl cyclic AMP did not inhibit the fibrinogen-induced aggregation of elastase-treated platelets. EDTA completely blocked the initiation of aggregation and reversed the fibrinogen-induced aggregation of elastasetreated platelets. Monoclonal and polyclonal antibodies directed against glycoproteins (GP) IIb and IIIa completely blocked the fibrinogen-induced aggregation of elastase-treated platelets. Immunoprecipitates with these antibodies obtained from detergent extracts of surface-radiolabeled, intact, and elastase-treated platelets contained the glycoproteins IIb and IIIa. We conclude that surface proteolysis by low concentrations of elastase can expose fibrinogen-binding sites associated with GPIIb and GPIIla on the platelet surface, resulting in spontaneous aggregation upon the addition of fibrinogen. These findings may be relevant to hemostatic changes observed in patients with increased levels of circulating elastase.
\end{abstract}

\section{Introduction}

Platelets stimulated by ADP (1-4), thrombin $(5,6)$, epinephrine $(2,7)$, or prostaglandin endoperoxides $(8,9)$ expose receptors specific for fibrinogen. These fibrinogen-binding sites were shown to be associated with glycoproteins (GP) ${ }^{1}$ IIb and IIIa of the platelet membrane (10-14). It is the exposure of these sites on adjoining platelets that results in fibrinogen binding and platelet aggregation. Several laboratories have demonstrated that fibrinogen-binding sites become permanently exposed on the platelet surface as a result of the pretreatment of platelets with proteolytic enzymes (15-17). Platelets pretreated with chymotrypsin or pronase specifically bind fibrinogen and aggregate spontaneously

A preliminary report of these findings was presented at the 57th Scientific Sessions of the American Heart Association, November 1984, Miami Beach, FL and was published in abstract form, 1984. Circulation. 70:98.

Please address reprint requests to Dr. Elizabeth Kornecki, Ph.D.

Received for publication 17 May 1985 and in revised form 12 November 1985.

J. Clin. Invest.

(c) The American Society for Clinical Investigation, Inc.

0021-9738/86/03/0750/07 \$1.00

Volume 77, March 1986, 750-756 upon the addition of fibrinogen even in the absence of ADP (or any other platelet agonist). Such proteolytic treatment results in platelets in which fibrinogen binding and the fibrinogen-induced aggregation are no longer sensitive to raised intracellular levels of cyclic AMP (18).

A role for proteases in the modulation of hemostasis and thrombosis has been suggested. Proteases released from human neutrophil granules have been shown to hydrolyze factors involved in blood coagulation and fibrinolysis (19-22). Activation of platelets by chymotrypsin-like activity has also been demonstrated $(15-17,20)$. The present study describes the activation of human platelets by extracellular elastase. We demonstrate that low concentrations of elastase $(1-10 \mu \mathrm{g} / \mathrm{ml})$ expose specific fibrinogen-binding sites on the platelet surface. The exposure of these receptor sites produces platelets that aggregate spontaneously upon the addition of fibrinogen. These in vitro findings provide experimental support for early studies (23) that have suggested the possibility that pancreatic elastase may play a role in arteriosclerosis.

\section{Methods}

Collection of blood. Blood was obtained from healthy individuals with the approval of the Institutional Human Experimentation Committee at the University of Vermont, Burlington, VT.

Human washed platelets. Platelets from blood freshly collected in the anticoagulant acid-citrate dextrose were washed in the presence of apyrase and heparin by the method of Mustard et al. (24). Platelets were suspended in Tyrode's solution containing $0.35 \%$ albumin ( $\mathrm{pH} 7.35$ ).

Platelet count. Platelets were counted by using a hemacytometer and an Olympus phase-contrast microscope (Olympus Corporation of America, New Hyde Park, NY).

Platelet aggregation and shape change. Experiments involving platelet aggregation were carried out with a model 400 Lumi aggregometer (Chrono-Log Corp., Havertown, PA). Platelet aggregation was initiated by the addition of $10 \mu \mathrm{l}$ of various agonists and/or $10 \mu \mathrm{l}$ of fibrinogen $(5-850 \mu \mathrm{g} / \mathrm{ml}$, final concentration) into platelet suspensions $(0.45 \mathrm{ml})$ containing $2-4 \times 10^{8}$ platelets $/ \mathrm{ml}$. Monoclonal or polyclonal antibodies $(50 \mu \mathrm{l})$ were incubated under stirring conditions with platelet suspensions (2-4 $\times 10^{8}$ platelets $/ \mathrm{ml}$ ) for $1 \mathrm{~min}$ at $37^{\circ} \mathrm{C}$ before the addition of platelet agonists. The initial velocity of aggregation was measured directly from recorder tracings. Platelet shape change was measured under stirring conditions $(1,200 \mathrm{rpm})$ at $37^{\circ} \mathrm{C}$ in a model DP-247-E Dual Recording Aggregation Meter (Sienco, Inc., Morrison, CO). Each channel was set at a sensitivity reading of 1,000 , which resulted in large changes in light transmission after the addition of ADP. Shape change was measured simultaneously for both intact and elastase-treated platelets $(0.45 \mathrm{ml}$ at $4 \times 10^{8} / \mathrm{ml}$ ) as a decrease in light transmission in response to various concentrations of ADP $(0.02-40 \mu \mathrm{M})$ in the presence of $5 \mathrm{mM}$ EGTA or $3 \mathrm{mM}$ EDTA. Identical results were obtained with intact or elastasetreated platelets using both chelating agents. In addition, identical results were obtained when ADP was added to elastase-treated platelets without any chelators present. The initial velocity and extent of shape change were measured directly from the recorder tracings.

1. Abbreviations used in this paper: GP, glycoproteins; SDS-PAGE, sodium dodecyl sulfate-polyacrylamide gel electrophoresis. 
Treatment of platelets with elastase. Porcine pancreatic elastase (type IV, lot 73F-81651; Sigma Chemical Co., St. Louis, MO) was chromatographically purified twice according to the method of Lewis et al. (25) and contained $90 \mathrm{U} / \mathrm{mg}$ protein of enzyme activity. $1 \mathrm{U}$ of elastase contained $11.1 \mu \mathrm{g}$ protein. The purity of this material was tested by SDSPAGE using $8.5 \%$ and $7-18 \%$ linear gradient gels. One protein band with a relative molecular weight $\left(M_{\mathrm{r}}\right)$ of 25,000 was identified by Coomassie Brilliant Blue staining and no other contaminants could be detected.

Washed human platelets $\left(1 \times 10^{9} / \mathrm{ml}\right)$ were suspended in $2 \mathrm{mM}$ $\mathrm{CaCl}_{2}, 1 \mathrm{mM} \mathrm{MgCl}, 0.36 \mathrm{mM} \mathrm{NaH} \mathrm{PO}_{4}, 135 \mathrm{mM} \mathrm{NaCl}, 2.68 \mathrm{mM}$ $\mathrm{KCl}$, and $11.9 \mathrm{mM} \mathrm{NaHCO}$ and incubated with elastase (0-250 $\mathrm{U}$ elastase $/ 10^{9}$ platelets $\left./ \mathrm{ml}\right)\left(0-2.77 \mathrm{mg}\right.$ protein) for $1 \mathrm{~h}$ at $37^{\circ} \mathrm{C}$. Untreated intact platelets were incubated under the same conditions. After the 1$h$ incubation period, platelets were washed three times by centrifugation and resuspended in Tyrode's albumin solution, pH 7.35.

Fibrinogen binding. Total binding of ${ }^{125} \mathrm{I}$-fibrinogen (sp. act. 4.14 $\left.\times 10^{5} \mathrm{cpm} / \mu \mathrm{g}\right)$ to elastase-treated platelets $\left(12.5 \mathrm{U} / 10^{9}\right.$ platelets $\left./ \mathrm{ml}\right)$ was performed over silicon oil (26) essentially as described using intact and chymotrypsin-treated platelets $(4,17)$. Fibrinogen binding was also determined both in the presence of $10 \mathrm{mM}$ EDTA and in the presence of a 100 -fold excess of unlabeled fibrinogen. Identical results were obtained under both conditions. The nonspecific binding was subtracted from the total binding to yield specific binding.

Cyclic AMP accumulation. Washed intact and elastase-treated platelets suspended in Tyrode's buffer, were incubated with $\left[{ }^{3} \mathrm{H}\right]$ adenine $(10$ $\mu \mathrm{Ci}\left[{ }^{3} \mathrm{H}\right.$ ]adenine per $10^{9}$ platelets) for $1 \mathrm{~h}$ at $37^{\circ} \mathrm{C}$. The platelets were then washed in Tyrode's albumin solution and assayed as described by Lenox et al. (27). The enzyme reaction (conversion of $\left[{ }^{3} \mathrm{H}\right] \mathrm{ATP}$ to $\left[{ }^{3} \mathrm{H}\right]$ cyclic AMP) was initiated by the addition of $50 \mu \mathrm{M}$ forskolin or 1 $\mu \mathrm{M} \mathrm{PGI}_{2}$ and terminated after 2 -min incubation at $37^{\circ} \mathrm{C}$ by the addition of $0.5 \mathrm{ml}$ of $0.75 \mathrm{mM}$ cyclic AMP and by heating to $100^{\circ} \mathrm{C}$ for $10 \mathrm{~min}$. The reaction volume was $100 \mu \mathrm{l}$ and the final platelet concentration was $10^{9}$ platelets $/ \mathrm{ml}$. To inhibit adenylate cyclase, we added ADP $(50 \mu \mathrm{M})$ or epinephrine $(10 \mu \mathrm{M})$ at the time of initiation of the reaction. The $\left[{ }^{3} \mathrm{H}\right]$ cyclic AMP formed was isolated using a modification (27) of the method of Salomon et al. (28). Reaction products were centrifuged at $2,500 \mathrm{~g}$ for $20 \mathrm{~min}$, the supernatants were applied onto cation exchange columns (AG50W-X8; Bio-Rad Laboratories, Richmond, CA), and the ${ }^{3} \mathrm{H}$ precursor nucleotides were eluted with water. After eluting the contents into alumina columns, the $\left[{ }^{3} \mathrm{H}\right]$ cyclic AMP was eluted with $0.1 \mathrm{M} \mathrm{im-}$ idazole, pH 7.4. Aliquots of the alumina eluates and ${ }^{3} \mathrm{H}$ nucleotide precursor fractions were counted with a 5-ml scintillation cocktail.

Monoclonal and polyclonal antibodies. Two types of antibodies that were previously shown to inhibit fibrinogen-induced aggregation of intact, chymotrypsin- and pronase-treated platelets were used. The preparation and characterization of a polyclonal rabbit anti-human, intact platelet membrane antibody and a monoclonal antibody (MA 123) have been described previously $(17,29)$.

${ }^{125}$ I-Iodination of platelets. Iodogen (1,3,4,6-tetrachloro-3 $\alpha, 6 \alpha$-diphenylglycoluril; Pierce Chemical Co., Rockford, IL) was used to iodinate the membrane surface of intact and elastase-treated platelets (17).

Sodium dodecyl sulfate-polyacrylamide gel electrophoresis (SDS$P A G E$ ). SDS-PAGE was performed in 5\% stacking gels and in $8.5 \%$ separation polyacrylamide slab gels. Molecular weight determinations were made by comparison with reduced samples of $\alpha_{2}$-macroglobulin $(170,000)$, phosphorylase $b(97,400)$, glutamate dehydrogenase $(55,400)$, and lactate dehydrogenase $(36,500)$.

Immunoprecipitation of ${ }^{125}$ I-labeled platelet proteins by monoclonal and polyclonal antibodies. Immunoprecipitation of detergent solubilized extracts of ${ }^{125} \mathrm{I}$-radiolabeled platelet membrane proteins by monoclonal and polyclonal antibodies was performed according to previously described methods (17).

\section{Results}

The effects of pretreatment with elastase on the aggregation of human platelets is shown in Fig. 1. Platelets pretreated with

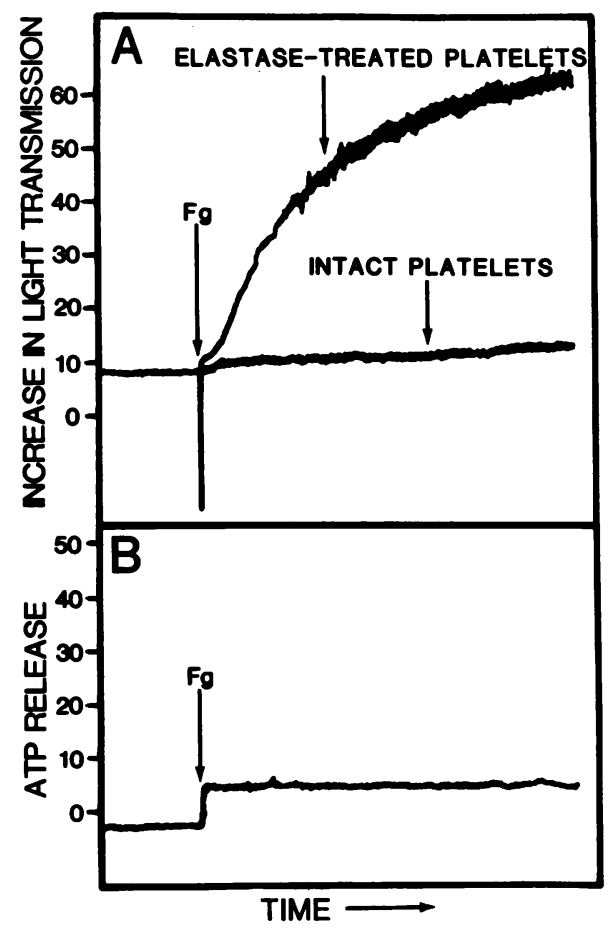

Figure 1. Aggregation of elastase-treated platelets by fibrinogen. Suspensions $\left(2 \times 10^{8} / \mathrm{ml}\right)(0.45 \mathrm{ml})$ of intact and elastase-treated platelets (12.5 U elastase $/ 10^{9}$ platelets per $\mathrm{ml}$ ) were stirred for $1 \mathrm{~min}$ at $37^{\circ} \mathrm{C}$ in a Lumi-Aggregometer (Chrono-Log Corp., Havertown, PA). Fibrinogen $(\mathrm{Fg})(25 \mu \mathrm{l})$, at a final concentration of $200 \mu \mathrm{g} / \mathrm{ml}$, was then added to initiate platelet aggregation as shown in $A$. In $B$, platelet release was monitored simultaneously along with the aggregation by adding $50 \mu \mathrm{l}$ of Chrono-Lumi luciferin-luciferase reagent (Chrono-Log Corp.) to the platelet suspensions before the addition of fibrinogen.

elastase aggregated directly upon the addition of fibrinogen (Fig. $1 A$ ). This aggregation was not associated with secretion of platelet granule contents. As can be seen in Fig. $1 B$, ATP was not released to the medium during the aggregation of elastase-treated platelets by fibrinogen. On the other hand, intact platelets that were not treated with elastase did not aggregate when fibrinogen was added without an agonist (Fig. $1 \mathrm{~A}$ ). Maximal aggregation of elastasetreated platelets occurred at a fibrinogen concentration of $\sim 200$ $\mu \mathrm{g} / \mathrm{ml}$ and half maximal aggregation required $\sim 40 \mu \mathrm{g} / \mathrm{ml} \mathrm{fi-}$ brinogen (Fig. 2). The fibrinogen-induced aggregation was also

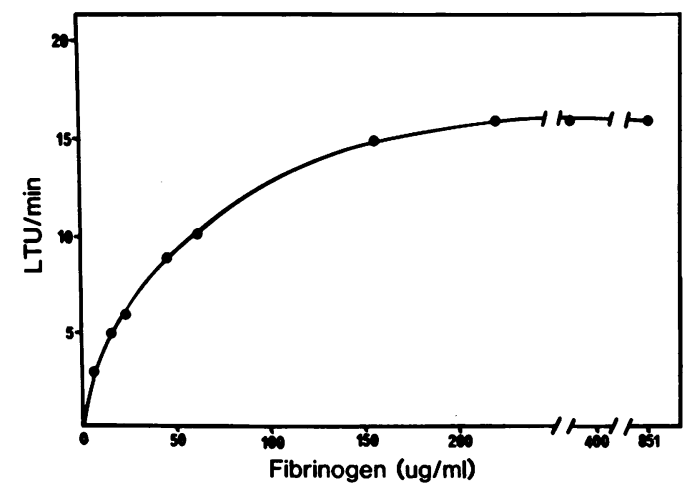

Figure 2. Aggregation of elastase-treated platelets by various concentrations of fibrinogen. Suspensions $\left(2 \times 10^{8} / \mathrm{ml}\right)$ of elastase-treated (12.5 $\mathrm{U} / 10^{9}$ platelets per $\mathrm{ml}$ ) platelets were incubated under stirring conditions for $1 \mathrm{~min}$ at $37^{\circ} \mathrm{C}$. Platelet aggregation was initiated by adding fibrinogen at the concentrations shown above. 
dependent on the concentration of elastase used during the preincubation period. Fig. 3. shows that maximal aggregation occurred after treatment with an elastase concentration of $10 \mathrm{U} /$ $10^{9}$ platelets $/ \mathrm{ml}(\sim 111 \mu \mathrm{g} / \mathrm{ml})$. Half-maximal aggregation to fibrinogen occurred with platelets treated with an elastase concentration of $1 \mathrm{U} / \mathrm{ml}(11 \mu \mathrm{g} / \mathrm{ml})$. A further increase in the concentration of elastase $(25 \mathrm{U} / \mathrm{ml})$ resulted in platelets that exhibited decreased ability to aggregate upon the addition of fibrinogen. The response of platelets to a maximal concentration of ADP $(10 \mu \mathrm{M})$ was not lost after elastase treatment, as shown by the ability of elastase-treated platelets to undergo a shape change upon the addition of $10 \mu \mathrm{M}$ ADP (Fig. 3). In addition, when various concentrations of ADP were tested, we found that the $50 \%$ effective dose values for ADP to induce a shape change in intact and elastase-treated platelets were $0.26 \pm 0.03$ and $0.37 \pm 0.09 \mu \mathrm{M}$, respectively. (Values are the mean \pm SEM from three separate experiments using ADP in a concentration range from 0.02 to $40 \mu \mathrm{M}$.)

The fibrinogen-induced aggregation of elastase-treated platelets was dependent on the presence of divalent cations, as evidenced by the finding that EDTA completely inhibited the aggregation of elastase-treated platelets induced by fibrinogen (Fig. 4 and Table I). EDTA also reversed the aggregation, as shown in Fig. 4. The effects of various agents on the fibrinogeninduced aggregation of elastase-treated platelets are shown in Table I. ATP and apyrase had no inhibitory effects, further indicating that the aggregation was not caused by released ADP. Stimulators of platelet adenylate cyclase, agents that completely block the aggregation of ADP-stimulated intact platelets, did not have any effect on the fibrinogen-induced aggregation of elastase-treated platelets. The lack of inhibition of fibrinogeninduced aggregation of elastase-treated platelets by these agents could be due to the proteolysis of prostaglandin receptors on

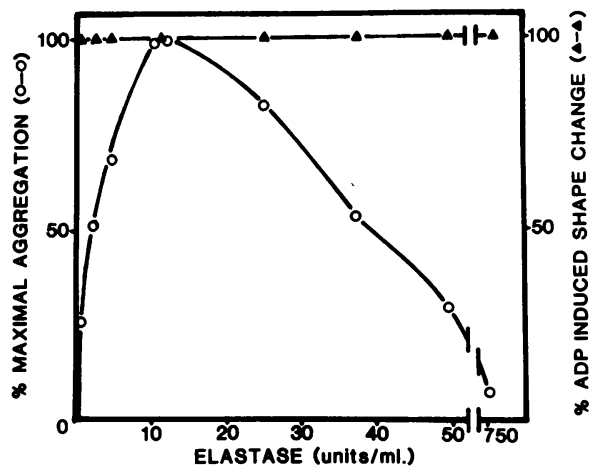

Figure 3. Effect of increasing concentrations of elastase on ADP-induced shape change and fibrinogen-induced platelet aggregation. Platelets were pretreated with various concentrations of elastase, washed, and resuspended at a concentration of $4 \times 10^{8} / \mathrm{ml}$. Aliquots $(0.45 \mathrm{ml})$ were added to cuvettes and stirred at $37^{\circ} \mathrm{C}$. Fibrinogen $(200 \mu \mathrm{g} / \mathrm{ml})$ $(25 \mu \mathrm{l})$ was added to initiate platelet aggregation. Maximal fibrinogeninduced aggregation (measured as the initial velocity) occurred at an elastase concentration of $12.5 \mathrm{U} / \mathrm{ml}$. This value was then set at $100 \%$. Platelet shape change ( $\Lambda)$ was initiated by adding ADP $(25 \mu \mathrm{l})(10 \mu \mathrm{M}$, final concentration) to platelet suspensions $(0.45 \mathrm{ml})$ incubated at $37^{\circ} \mathrm{C}$ for $1 \mathrm{~min}$ with $5 \mathrm{mM}$ EGTA, pH 7.4. The initial velocity and extent of shape change were measured in both intact (untreated) and elastase-treated platelets exposed to $10 \mu \mathrm{M}$ ADP. These values obtained with elastase-treated platelets were compared with those obtained with intact (control) platelets. They are expressed as the percent of control. Each value is the average of triplicate samples. Similar results were obtained using five blood donors.

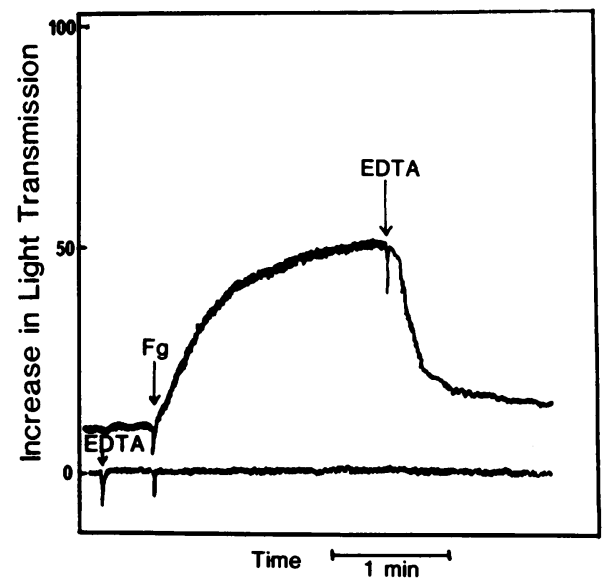

Figure 4. Inhibition by EDTA of the fibrinogen-induced aggregation of elastase-treated platelets. After being washed, intact platelets were pretreated with elastase $\left(12.5 \mathrm{U} / 10^{9}\right.$ platelets per $\left.\mathrm{ml}\right)$. Fibrinogen $(\mathrm{Fg})$ $(200 \mu \mathrm{g} / \mathrm{ml})$ was added to initiate platelet aggregation. EDTA ( $1 \mathrm{mM}$, final concentration) was added either at maximal aggregation or before the addition of $\mathrm{Fg}$ as shown in the lower tracing.

the platelet surface, or due to degradation of the adenylate cyclase complex by elastase treatment. To test these possibilities, we measured the adenylate cyclase activity of both intact and elastase-treated platelets. We found that treatment of platelets with elastase had no effect on the ability of forskolin or prostacyclin to increase intracellular levels of cyclic AMP (Fig. 5). We also measured the ability of ADP or epinephrine to inhibit the stimulation of adenylate cyclase in elastase-treated platelets. Fig. 5 demonstrates that the inhibition of adenylate cyclase activity by ADP and epinephrine in elastase-treated platelets was identical to that of intact (untreated) platelets.

The binding of fibrinogen to elastase-treated platelets is shown in Fig. 6. The specific binding of radiolabeled fibrinogen

Table I. Effect of Various Agents on the Fibrinogen-induced Aggregation of Elastase-treated Platelets*

\begin{tabular}{lll}
\hline Addition & $\begin{array}{l}\text { Initial velocity } \\
\text { of aggregation }\end{array}$ & $\begin{array}{l}\text { Extent of } \\
\text { aggregation }\end{array}$ \\
\hline LTU/minf & $L T U$
\end{tabular}

Fibrinogen $(200 \mu \mathrm{g} / \mathrm{ml})$

$36 \S \quad 36$

Apyrase $(100 \mu \mathrm{g})+$ fibrinogen

ATP $(1 \mathrm{mM})+$ fibrinogen

EDTA (1 mM) + fibrinogen

35

36

0

Prostacyclin $(50 \mu \mathrm{M})+$ fibrinogen

Forskolin $(100 \mu \mathrm{M})+$ fibrinogen

$\mathrm{PGE}_{1}(1 \mu \mathrm{M})+$ fibrinogen

36

38

36

36

36

36

0

35

34

34

* Washed platelet suspensions were treated with elastase (12.5 U/10 platelets per $\mathrm{ml}$ ) for $1 \mathrm{~h}$ at $37^{\circ} \mathrm{C}$. Platelets were washed and resuspended in Tyrode's buffer at a concentration of $4 \times 10^{8} / \mathrm{ml}$. Aliquots $(0.45 \mathrm{ml})$ of this suspension were added to cuvettes and stirred for 1 min at $37^{\circ} \mathrm{C}$ with $10 \mu \mathrm{l}$ of the compounds shown above. Platelet aggregation was initiated by the addition of fibrinogen $(25 \mu 1,200 \mu \mathrm{g} / \mathrm{ml}$, final concentration).

$\ddagger$ Abbreviations used in this table are: LTU, light transmission unit; $\mathrm{PGE}_{1}$, prostaglandin 1.

$\S$ Numbers indicate the mean of duplicate samples obtained in two experiments. Similar results were obtained in five experiments using platelets prepared from the blood of five donors. 


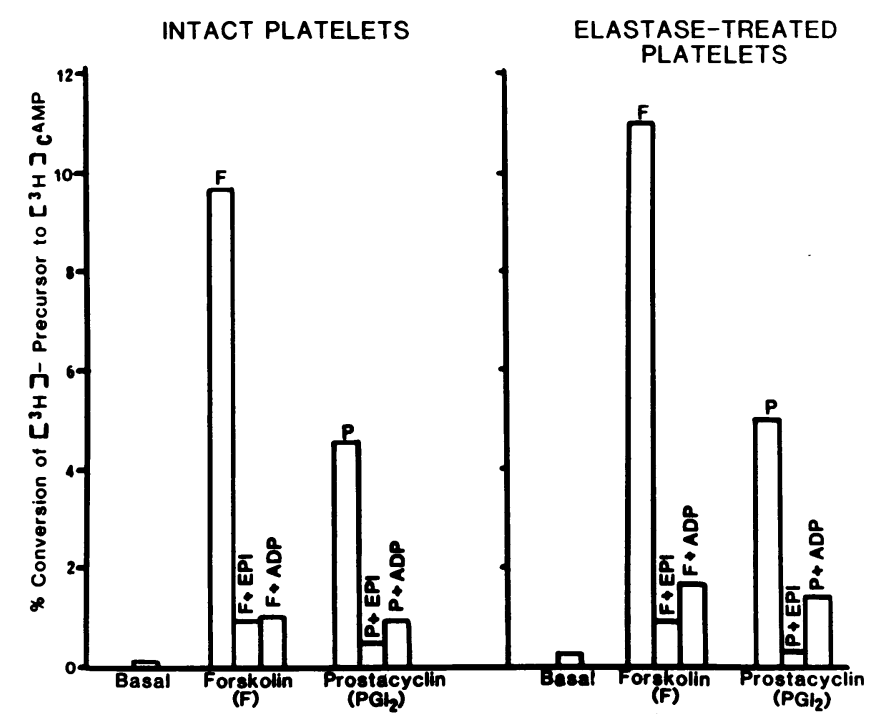

Figure 5. Comparison of cyclic AMP levels in intact and elastasetreated platelets. The production of $\left[{ }^{3} \mathrm{H}\right]$ cyclic AMP was measured in intact platelets and in elastase-treated $\left(12.5 \mathrm{U} / 10^{9}\right.$ platelets per $\left.\mathrm{ml}\right)$ platelets. Forskolin (F) $(50 \mu \mathrm{M})$ and prostacyclin $(\mathrm{P})(1 \mu \mathrm{M})$ were incubated with platelets for $2 \mathrm{~min}$ at $37^{\circ} \mathrm{C}$ and the conversion of $\left[{ }^{3} \mathrm{H}\right] \mathrm{ATP}$ to $\left[{ }^{3} \mathrm{H}\right]$ cyclic AMP was measured. In other experiments, epinephrine $(10 \mu \mathrm{M})$ and ADP $(10 \mu \mathrm{M})$ were added simultaneously with either forskolin or prostacyclin to reverse the stimulation of adenylate cyclase of intact and elastase-treated platelets. Each value is the mean of two experiments each performed in duplicate.

to elastase-treated platelets approached saturation at $\sim 400 \mu \mathrm{g}$ fibrinogen $/ \mathrm{ml}$. Scatchard plot analysis of the data from five separate experiments demonstrated one class of fibrinogen binding sites $(48,400 \pm 9,967$ sites/platelet $)$ with a mean value for the dissociation constant for fibrinogen of $6.3 \pm 1.48 \times 10^{-7} \mathrm{M}$ (Table II).

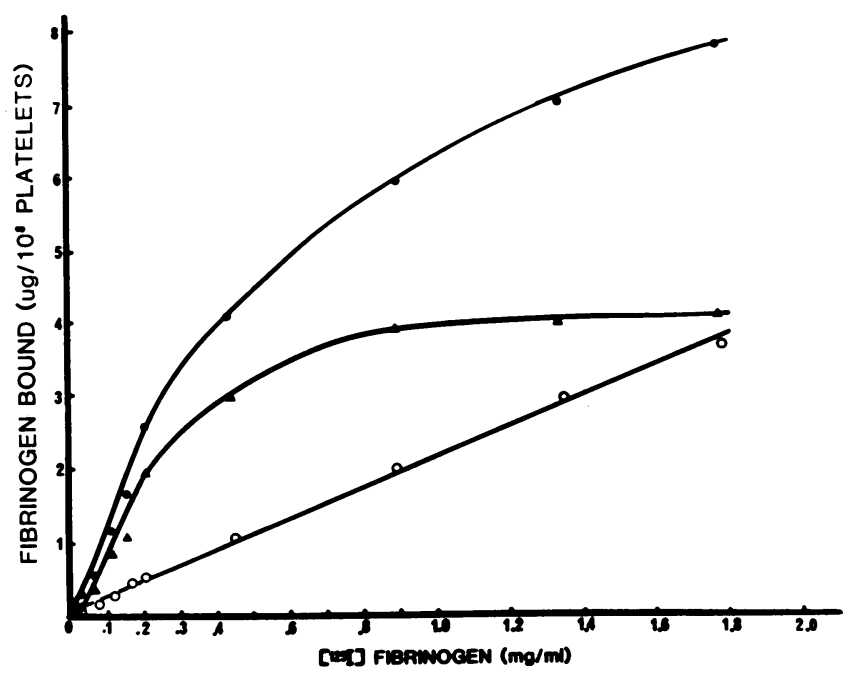

Figure 6. Fibrinogen binding to elastase-treated platelets. This figure represents one of three similar experiments using platelets pretreated with $12.5 \mathrm{U}$ elastase $/ 10^{9}$ platelets per $\mathrm{ml}$. (๑) Total fibrinogen bound; (O) nonspecific fibrinogen bound in the presence of $10 \mathrm{mM}$ EDTA; or in the presence of a 100-fold excess of unlabeled fibrinogen; (A) specific fibrinogen bound.
Table II. Binding of Fibrinogen to Elastase-treated Platelets*

\begin{tabular}{lll}
\hline Experiment & $\mathbf{B}_{\max }$ (Sites/platelet) & Dissociation constant \\
\hline & & $(M)$ \\
1 & 84,000 & $7.1 \times 10^{-7}$ \\
2 & 42,000 & $1.0 \times 10^{-6}$ \\
3 & 24,000 & $6.0 \times 10^{-7}$ \\
4 & 40,000 & $1.0 \times 10^{-7}$ \\
5 & 52,000 & $7.4 \times 10^{-7}$
\end{tabular}

* Platelets, pretreated with $12.5 \mathrm{U} / 10^{9}$ platelets per $\mathrm{ml}$ of elastase for $1 \mathrm{~h}$ at $37^{\circ} \mathrm{C}$, were washed and resuspended at a concentration of $10^{9}$ platelets/ml. Radiolabeled fibrinogen $(25 \mu \mathrm{l})$ at concentrations ranging from 1 to $1,000 \mu \mathrm{g} / \mathrm{ml}$, were added to $0.40 \mathrm{ml}$ of the platelet suspension, followed by a 10 -min incubation at $22^{\circ} \mathrm{C}$. $300-\mu$ laliquots were applied over $50 \mu \mathrm{l}$ of silicon oil, centrifuged, and the radioactivities in the pellets were counted.

To examine the surface proteins, we radiolabeled intact and elastase-treated platelets with ${ }^{125} \mathrm{I}$ and analyzed the protein pattern by SDS-PAGE followed by autoradiography. The main protein components that were iodinated on the surface of intact platelets were GPIIb $\left(M_{\mathrm{r}} 120,00\right)$ and GPIIIa $\left(M_{\mathrm{r}} 100,000\right)$ as shown previously (17). No significant differences were observed in the labeling of these proteins in elastase-treated, compared with untreated, intact platelets (Fig. 7). The detergent solubilized extracts of surface-labeled intact and elastase-treated platelets

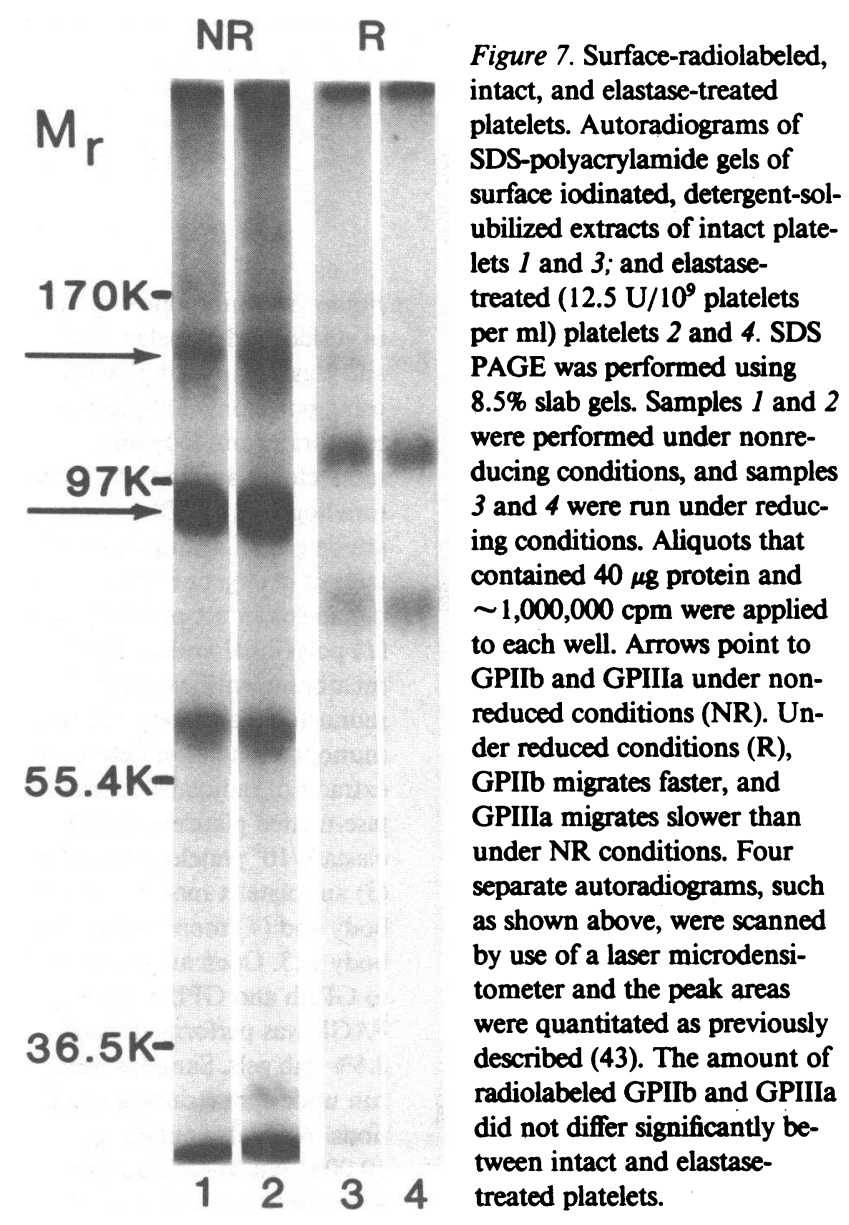


were immunoprecipitated using a polyclonal anti-intact platelet membrane antibody (17) and a monoclonal antibody (29). Fig. 8 shows that the antimembrane antibody immunoprecipitated GPIIb and GPIIIa from detergent extracts of intact platelets (lane 1) and lesser amounts of GPIIb and GPIIIa from elastase-treated platelets (lane 3). The immunoprecipitates obtained with monoclonal antibody 123 are shown in Fig. 8, lane 2 (for intact platelets) and lane 4 (for elastase-treated platelets). GPIIb and GPIIIa were immunoprecipitated from intact and elastase-treated platelet extracts. Also, a 200,000-mol-wt protein co-precipitated with the GPIIb/GPIIIa complex of intact and elastase-treated platelets. Fig. 9 shows that both polyclonal antiplatelet membrane antibody and monoclonal antibody 123 could completely inhibit the fibrinogen-induced aggregation of elastase-treated platelets.

\section{Discussion}

The objective of this investigation was to determine whether treatment of platelets with the proteolytic enzyme elastase has significant effects on platelet function. The data presented here demonstrate that low concentrations of elastase $(1.0-10 \mu \mathrm{g} / \mathrm{ml})$ can cause an irreversible exposure of fibrinogen-binding sites on the platelet surface, producing platelets that can be aggregated directly by fibrinogen. The binding of radiolabeled fibrinogen to elastase-treated platelets was specific and saturable with the number of fibrinogen-binding sites ranging from 24,000 to 84,000 per platelet (mean \pm SEM was calculated to be $41,000 \pm 13,645)$. The dissociation constant for fibrinogen ranged from 1.0 to $10 \times 10^{-7} \mathrm{M}$ with the mean \pm SEM for five separate donors of $6.28 \pm 1.47 \times 10^{-7} \mathrm{M}$. The aggregation of elastase-

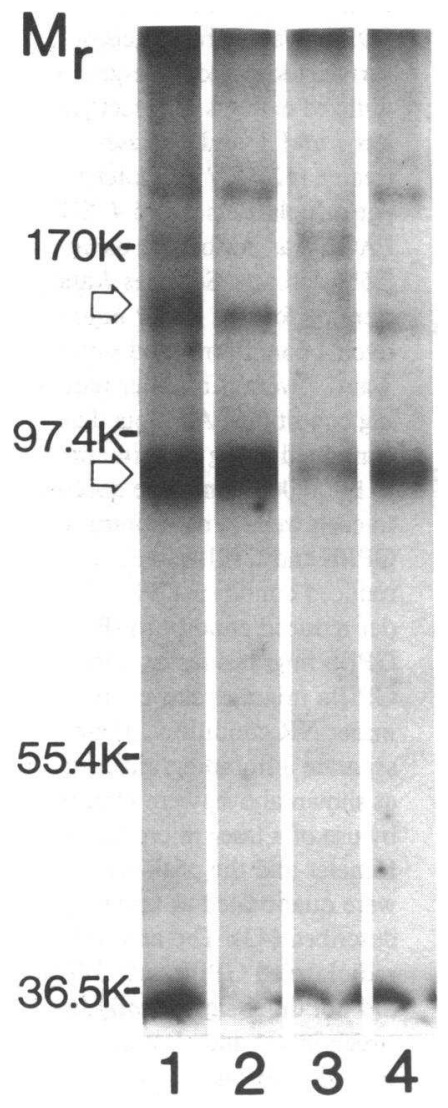

Figure 8. Immunoprecipitates of surface-radiolabeled, intact, and elastase-treated platelets using polyclonal antiplatelet membrane antibody and monoclonal antibody 123 . Autoradiograms of SDS-polyacrylamide gels of immunoprecipitates of detergent extracts of radiolabeled intact platelets using (1) polyclonal antiplatelet membrane antibody and (2) monoclonal antibody 123 . Immunoprecipitates of detergent extracts of radiolabeled, elastase-treated platelets $(12.5 \mathrm{U}$ elastase $/ 10^{9}$ platelets $/ \mathrm{ml}$ ) using (3) antiplatelet membrane antibody and (4) monoclonal antibody 123 . Open arrows point to GPIIb and GPIIIa. SDSPAGE was performed using $8.5 \%$ slab gels. Samples were run under nonreducing conditions. Aliquots containing $50,000 \mathrm{cpm}$ of each sample were applied to the gel.

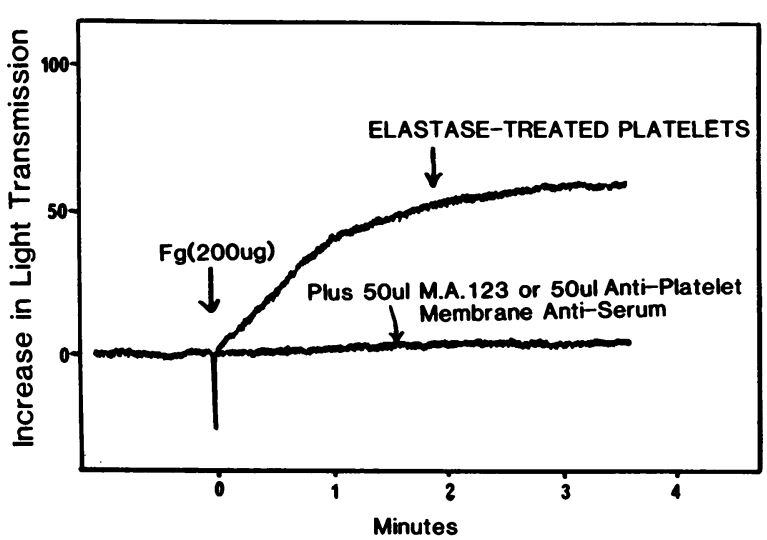

Figure 9. Inhibition of fibrinogen-induced aggregation of elastasetreated platelets by specific monoclonal and polyclonal antibodies. The fibrinogen $(\mathrm{Fg})$-induced aggregation of elastase-treated (12.5 U/ $10^{9}$ platelets per $\mathrm{ml}$ ) platelets was initiated by the addition of $\mathrm{Fg}(200$ $\mu \mathrm{g} / \mathrm{ml}$ ). $50-\mu \mathrm{l}$ aliquots of either monoclonal antibody 123 (M.A. 123) $(20 \mu \mathrm{g} / \mathrm{ml})$ or rabbit anti-intact platelet membrane $\mathrm{IgG}(500 \mu \mathrm{g} / \mathrm{ml})$ were incubated with platelet suspensions for $1 \mathrm{~min}$ before the addition of $\mathrm{Fg}$.

treated platelets was dependent on the concentration of fibrinogen, and on the concentration of elastase used during the preincubation period. The maximal level of aggregation that could be attained with fibrinogen was achieved using concentrations of elastase of $10-12 \mathrm{U} / 10^{9} \mathrm{ml}$ platelets $(111-132 \mu \mathrm{g} /$ $\mathrm{ml})$. Incubation with $1 \mathrm{U}$ of elastase $(11 \mu \mathrm{g} / \mathrm{ml})$ produced a halfmaximal response of these platelets to fibrinogen. The fibrinogeninduced aggregation of elastase-treated platelets was dependent also on the presence of divalent cations. EDTA completely inhibited the aggregation of elastase-treated platelets. At maximal aggregation, the addition of EDTA completely reversed the aggregation. In contrast to intact (untreated) platelets, addition of ADP was not necessary to induce aggregation of elastase-treated platelets. However, ADP was able to induce a maximal shape change in elastase-treated platelets that was similar to that observed in intact platelets. Neither the extent nor the initial velocity of this shape change was altered by pretreatment of platelets with up to $500 \mu \mathrm{g}(45 \mathrm{U})$ of elastase. Also, the affinity for ADP was not altered, since the $50 \%$ effective dose for ADP for inducing shape change in elastase-treated platelets $(0.37 \pm 0.09 \mu \mathrm{M})$ did not differ significantly from that of intact platelets $(0.26 \pm 0.03$ $\mu \mathrm{M})$. These values are very similar to those reported previously for ADP-induced shape change of intact platelets by other investigators (30-32). We conclude that under certain conditions, fibrinogen-induced aggregation of human platelets can be independent of shape change. This conclusion is consistent with previous reports by Peerschke and Zucker (33) and Wheeler et al. (34) using cytochalasins, and our studies of chymotrypsintreated platelets $(4,16-18)$.

The fibrinogen-induced aggregation of elastase-treated platelets was not inhibited by forskolin or prostacyclin, agents that completely inhibited the ADP-induced, fibrinogen-dependent aggregation of intact platelets. The lack of inhibition of fibrinogen-induced aggregation of elastase-treated platelets by these agents was not due to the absence of prostaglandin receptors on the platelet surface or due to degradation of the adenylate cyclase complex by elastase treatment. This was evidenced by measuring the adenylate cyclase activity of both intact and elas- 
tase-treated platelets. We found that elastase-treated platelets responded to forskolin and prostacyclin, and increased cyclic AMP levels to the same extent as did intact platelets. In addition, we found that the inhibition of the adenylate cyclase system of elastase-treated platelets by ADP and epinephrine was identical to that of intact (untreated) platelets. The treatment of platelets with either 125 or $500 \mu \mathrm{g}$ of elastase had no effect on the ability of ADP or epinephrine to inhibit the prostacyclin or forskolininduced stimulation of the platelet adenylate cyclase. This finding indicates that the prostaglandin receptor, the ADP and epinephrine receptors, as well as the mechanism that couples these receptors to adenylate cyclase, remain functionally unchanged after treatment of the platelet surface with elastase. These findings also indicate that the adenylate cyclase system becomes dissociated from aggregation after surface proteolysis.

To investigate the possible mechanism(s) whereby elastase treatment causes exposure of fibrinogen-binding sites, we used monoclonal and polyclonal antibodies characterized in previous studies $(17,29)$. We found that monoclonal antibody 123 and a polyclonal antiplatelet membrane antibody inhibited the fibrinogen-induced aggregation of elastase-treated platelets. In addition, we observed that monoclonal antibody 123 and polyclonal antimembrane antibody immunoprecipitated the membrane glycoproteins GPIIb and GPIIIa from detergent-solubilized, surface-radiolabeled, elastase-treated platelets. This would indicate that sites formed by the association of the GPIIb/GPIIIa complex or sites found on GPIIb or GPIIIa molecules appear to be involved in the binding of fibrinogen to the surface of elastase-treated platelets. In previous studies (17) we have found that treatment of platelets with high concentrations of chymotrypsin $(500-1,000 \mu \mathrm{g} / \mathrm{ml})$ resulted in the appearance of a $66,000-$ $M_{\mathrm{r}}$ protein derived from GPIIIa on the platelet surface. The formation of such a derivative was not detected on the surface of elastase-treated platelets. Due to differences in the specificities of the enzymes, it is possible that elastase produces only small fragments from GPIIb or GPIIIa molecules, smaller than those produced by chymotrypsin or pronase-treatment. These changes may be sufficient to expose fibrinogen-binding sites on the platelet surface without necessarily forming a 66,000-mol-wt fragment from GPIIIa. Alternatively, it is possible that elastase exposes fibrinogen-binding sites without producing changes in the GPIIb/ IIla complex itself, but by hydrolyzing other surface proteins that mask the fibrinogen-binding sites in intact, resting platelets.

The results of the present study could have important clinical implications. The effects of pancreatic proteases on platelet function have been implicated in the development of systemic complications in pancreatitis (35). Proteolysis of platelet surface glycoproteins, in vivo, has been associated with cirrhosis of the liver (36). After the studies reported here were completed, Brower et al. (37) have reported that platelets treated with human neutrophil elastase lose the ability to aggregate in response to thrombin and ristocetin. However, spontaneous aggregation to added fibrinogen was not tested by Brower et al. (37). In recent studies (38), we found that human platelets pretreated with low concentrations of elastase purified from human granulocytes can be aggregated directly by fibrinogen. Egbring et al. (19) previously reported that the plasma of patients with septicemia or acute leukemia contain high levels of granulocyte elastase, and this was associated with thrombocytopenia. Although plasma antiproteinases ( $\alpha_{1}$-antitrypsin and $\alpha_{2}$-macroglobulin) form complexes with elastase, significant proteolytic activity was still detectable in the plasma of these patients even in the presence of the antiproteases (19). Furthermore, the proteases in such complexes are still active, since they appear to have the ability to proteolyze specific substrates (39-42). Our in vitro data suggest, therefore, that under certain pathophysiological conditions circulating elastase could cause irreversible platelet activation in vivo. The clinical implications of our findings must be carefully investigated, since the process described here may play a role in hemostatic changes observed in patients with septicemia, acute leukemia, pancreatitis $(19,35)$, and possibly other diseases with increased circulating elastase.

\section{Acknowledgments}

The author gratefully acknowledges the technical assistance of Mr. David H. Hardwick and Dr. Dan Hendley, and the expert advice of Dr. John Ellis. We also wish to express our thanks to Mrs. Pat Smith for typing this manuscript and Mr. Hardwick for the preparation of the figures.

Supported in part by a New Investigator Research Award (HL32594) to Dr. Kornecki from the National Heart, Lung, and Blood Institute.

\section{References}

1. Marguerie, G. A., E. F. Plow, and T. S. Edgington. 1979. Human platelets possess an inducible and saturable receptor specific for fibrinogen. J. Biol. Chem. 254:5357-5363.

2. Bennett, J. S., and G. J. Vilaire. 1979. Exposure of platelet fibrinogen receptors by ADP and epinephrine. J. Clin. Invest. 64:1393-1401.

3. Peerschke, E. I., M. G. Zucker, R. A. Grant, J. J. Egan, and M. M. Johnson. 1980. Correlation between fibrinogen binding to human platelets and platelet aggregability. Blood. 55:841-847.

4. Kornecki, E., S. Niewiarowski, T. A. Morinelli, and M. Kloczewiak. 1981. Effects of chymotrypsin and adenosine diphosphate on the exposure of fibrinogen receptors on normal human and Glanzmann's thrombasthenic platelets. J. Biol. Chem. 256:5696-5701.

5. Hawiger, J., S. Parkinson, and S. Timmons. 1980. Prostacyclin inhibits mobilisation of fibrinogen-binding sites on human ADP- and thrombin-treated platelets. Nature (Lond.). 283:195-197.

6. Plow, E. F., and G. A. Marguerie. 1980. Participation of ADP in the binding of fibrinogen to thrombin-stimulated platelets. Blood. 56: 553-555.

7. Plow, E. F., and P. W. Marguerie. 1980. Induction of the fibrinogen receptor on human platelets by epinephrine and the combination of epinephrine and ADP. J. Biol. Chem. 255:10971-10977.

8. Bennett, J. S., G. Vilaire, and J. W. Burch. 1981. A role for prostaglandins and thromboxanes in the exposure of platelet-fibrinogen receptors. J. Clin. Invest. 68:981-987.

9. Morinelli, T. A., S. Niewiarowski, E. Kornecki, W. R. Figures, Y. Wachtfogel, and R. W. Colman. 1983. Platelet aggregation and exposure of fibrinogen receptors by prostaglandin endoperoxide analogues. Blood. 61:41-49.

10. Phillips, D. R., and P. Agin. 1977. Platelet membrane defects in Glanzmann's thrombasthenia. J. Clin. Invest. 60:535-545.

11. Hagen, I., A. Nurden, O. J. Bjerrum, N. O. Solum, and J. P. Caen. 1980. Immunochemical evidence for protein abnormalities in platelets with Glanzmann's thrombasthenia and Bernard-Soulier syndrome. J. Clin. Invest. 65:722-731.

12. Nachman, R. L., and L. L. K. Leung. 1982. Complex formation of platelet membrane glycoproteins IIb and IIIa with fibrinogen. J. Clin. Invest. 69:263-269.

13. Bennett, J. S., G. Vilaire, and D. B. Cines. 1982. Identification of fibrinogen receptor on human platelets by photoaffinity labeling. $J$. Biol. Chem. 257:8049-8054.

14. McEver, R. P., E. M. Bennett, and M. N. Martin. 1983. Identification of two structurally and functionally distinct sites on human platelet membrane glycoprotein IIb-IIIa using monoclonal antibodies. J. Biol. Chem. 258:5269-5275. 
15. Greenberg, J., J. L. Or, M. A. Packham, M. A. Guccione, E. J. Harfenist, R. L. Kinlough-Rathbone, D. W. Perry, and J. F. Mustard. 1979. The effect of pretreatment of human or rabbit platelets with chymotrypsin on their responses to human fibrinogen and aggregating agents. Blood. 54:753-765.

16. Niewiarowski, S., A. Z. Budzynski, T. A. Morinelli, T. M. Budzynski, and G. J. Stewart. 1981. Exposure of fibrinogen receptor on human platelets by proteolytic enzymes. J. Biol. Chem. 256:917-925.

17. Kornecki, E., G. P. Tuszynski, and S. Niewiarowski. 1983. Inhibition of fibrinogen receptor-mediated platelet aggregation by heterologous anti-human platelet membrane antibody: significance of an $\mathrm{Mr}$ $=66,000$ protein derived from glycoprotein IIIa. J. Biol. Chem. $258(15)$ : 9349-9356.

18. Kornecki, E., Y. H. Ehrlich, D. H. Hardwick, and R. H. Lenox. Proteolysis of the platelet surface: dissociation of shape change from aggregation. Am. J. Physiol. In press.

19. Egbring, R., W. Schmidt, G. Fuchs, and K. Haveman. 1977. Demonstration of granulocyte proteases in plasma of patients with acute leukemia and septicemia with coagulation defects. Blood. 49:219-321.

20. Kopec, M., K. Bykowska, S. Lopacuik, M. Jelenska, J. Kaczanowska, I. Sopata, and E. Wojtecka. 1980. Effects of neutral proteases from human leucocytes on structure and biological properties of human factor VIII. Thromb. Haemostasis. 43:211-217.

21. Plow, E. F., and T. S. Edgington. 1978. The fibrinolytic pathway of leukocytes. In Neutral Proteases of Human Polymorphonuclear Leukocytes. K. Kavemann and A. Janoff, editors. Urban \& Schwarzenberg Inc., Baltimore, MD. 330-345.

22. Plow, E. F. 1981. Leukocyte elastase release during blood coagulation: a potential mechanism for activation of the alternate pathway. J. Clin. Invest. 69:564-572.

23. Balo, J., and I. Banga. 1953. Change in the elastase content of the human pancreas in relation to arteriosclerosis. Acta Physiol. Acad. Sci. Hung. 4:187-194.

24. Mustard, J. F., D. W. Perry, N. G. Ardlie, and M. A. Packham. 1972. Preparation of suspensions of washed platelets from humans. $B r$ J. Haematol. 22:193-204.

25. Lewis, U. J., D. E. Williams, and N. G. Brink. 1956. Pancreatic elastase: purification, properties, and function. J. Biol. Chem. 222:705720.

26. Feinberg, H., F. Michael, and G. V. R. Born. 1974. Determination of the fluid volume of platelets by their separation through silicon oil. J. Lab. Clin. Med. 84:926-934.

27. Lenox, R. H., J. Ellis, D. Van Riper, and Y. H. Ehrlich. 1985. Alpha ${ }_{2}$-adrenergic receptor-mediated regulation of adenylate cyclase in the intact human platelet. Evidence for a receptor reserve. Mol. Pharmacol. 27:1-7.

28. Salomon, Y. 1979. Adenylate cyclase assay. Adv. Cyclic Nucleotide Res. 10:35-55.

29. Kornecki, E., H. Lee, F. Merlin, D. Hershock, G. P. Tuszynski, and S. Niewiarowski. 1984. Comparison of platelet fibrinogen receptors on intact and proteolytically-treated platelets by use of an anti-glycoprotein IIla monoclonal antibody (MA 123). Thromb. Res. 34:35-49.

30. Favis, G. R., and R. W. Colman. 1978. The action of halofenate on platelet shape change and prostaglandin synthesis. J. Lab. Clin. Med. 92:45-52.

31. Milton, J. G., W. Yung, C. Glushak, and M. M. Frojmovic. 1980. Kinetics of ADP-induced human platelet shape change: apparent positive cooperativity. Can. J. Physiol. Pharmacol. 58:45-52.

32. Hantgan, R. R. 1984. A study of the kinetics of ADP-triggered platelet shape change. Blood. 64:896-906.

33. Peerschke, E. I., and M. B. Zucker. 1980. Relationship of ADPinduced fibrinogen binding to platelet shape change and aggregation elucidated by use of colchicine and cytochalasin B. Thromb. Haemostasis. 43:58-60.

34. Wheeler, M. E., A. C. Cox, and R. C. Carroll. 1984. Retention of the glycoprotein IIb-IIIa complex in the isolated platelet cytoskeleton: effects of separable assembly of platelet pseudopodal and contractile cytoskeletons. J. Clin. Invest. 74:1080-1089.

35. Prinz, R., J. Fareed, A. Rock, G. Squillaci, and J. Wallenga 1984. Platelet activation by human pancreatic fluid. J. Surg. Res. 37: 314-319.

36. Ordinas, A., S. Margall, R. Castillo, and A. T. Nurden. 1978. A glycoprotein I defect in the platelets of three patients with severe cirrhosis of the liver. Thromb. Res. 13:297-302.

37. Brower, M. S., R. I. Levin, and K. Garry. 1985. Human neurophil elastase modulates platelet function by limited proteolysis of membrane glycoproteins. J. Clin. Invest. 75:657-666.

38. Kornecki, E., Y. H. Ehrlich, M. Gramse, R. Seitz, and R. Egbring. 1985. Exposure of fibrinogen binding sites by granulocyte elastase induces aggregation of human platelets. Blood. 66:308 (Abstr.)

39. Galdston, M., V. Levytska, I. E. Liener, and D. Y. Twumasi. 1979. Degradation of thromboplastin and elastin substrates by neutrophil elastase, free and bound to $\alpha_{2}$-macroglobulin in serum of the $\mathrm{M}$ and $\mathrm{Z}$ (P) phenotypes for alpha-antitrypsin. Annu. Rev. Resp. Dis. 119:235241.

40. Harpel, P. C., and M. W. Mosesson. 1974. Degradation of human fibrogen by plasma $\alpha_{2}$-macroglobulin-enzyme complexes. J. Clin. Invest. 52:2175-2182.

41. Switzer, M. E. P., H. G. Gordon, and P. A. McKee. 1983. Proteolytic activity of $\alpha_{2}$-macroglobulin-enzyme complexes toward human factor VIII von Willebrand factor. Biochemistry. 22:1437-1444.

42. Sterrenberg, L., M. Gravesen, F. Haverkate, and W. Nieuwenhuizen. 1983. Granulocyte enzyme mediated degradation of human fibrinogen in plasma in vitro. Thromb. Res. 31:719-728.

43. Whittemore, S., S. G. Graber, R. H. Lenox, E. D. Hendley, and Y. H. Ehrlich. 1984. Activation of adenylyl cyclase by preincubation of rat cerebral-cortical membranes under phosphorylating conditions: role of ATP, GTP and divalent cations. J. Neurochem. 42:1685-1696. 